\title{
Research on Status and Strategy of Wetland Tourism Development
}

\author{
Jianbo $\mathrm{He}^{1, \mathrm{a}}$, Zhen Wang ${ }^{1, \mathrm{~b}}$ \\ ${ }^{1}$ Jiangxi Science \& Technology Normal University, Nanchang 330038, Jiangxi, China \\ aemail:Johnnyhay@163.com, bemail:Windy8299@126.com
}

Keywords: Wetland tourism; Development mode; Geographical location; Ecology; Sustainable Development

\begin{abstract}
Since the integrated function of wetland can cater to the consumption psychology and the higher level of spiritual pursuit of tourists, wetland tourism has been enjoying a great popularity among tourists from beginning. The traditional tourism exploitation mode is not fit for the unique geographical location, natural environment and ecological conditions of wetland, and may even hinder its sustainable development. Thus the construction of wetland tourism mode for sustainable development now becomes an issue needing to be addressed urgently by administrators and tourism employees.
\end{abstract}

\section{Introduction}

Nowadays, known as the sunrise industry, tourism has been brought into a abroad attention. With not only abundant resources of water, land, biodiversity and mineral, but also the enormous ecological benefit and economic efficiency, wetland is the most productive ecosystem of the world. And the wetland tourism is a kind of traveling activity based on wetland resources and a tourism development mode with strong ecological consciousness.

However, along with immeasurable economic benefit, development of wetland tourism also brings many environment problems to people. That requires us to properly handle the relationship between wetland tourism development and environment protection, which is to determine the threshold of travel population, predict the environmental capacity of the wetland and try not to pose hazards to wetland environment under the principle of paying equal attention to development and protection. Only in this way can the contradiction between wetland tourism and environment protection be alleviated and can maintain and restore the ecological functions of wetland to achieve the goal of sustainable development of wetland tourism step by step.

\section{Wetland}

The term "wetland" of Chinese derives from the English equivalent. There is no exact definition of wetland yet in china, but most scholars prefer the definition in the RAMSAR Convention: "...wetlands are areas of marsh, fen, peatland or water, whether natural or artificial, permanent or temporary, with water that is static or flowing, fresh, brackish or salt, including areas of marine water the depth of which at low tide does not exceed six meters." The Convention also extends the definition of wetlands to the wider habitat types, including rivers and lakes, coastal lagoons, mangroves, peat lands, coral reefs and some artificial wetlands, such as fish ponds, shrimp ponds, farm ponds, irrigated agricultural land, salt pond, reservoirs, gravel pits, sewage treatment plants and canals. Wetland, forest and ocean, are Known as the world's three big ecosystems, and wetland, with its distinguished ecological benefit, is called the "kidney of the Earth". At present, the global total wetland area is about seven - nine million square kilometers, accounting for $4 \%-6 \%$ of the 
total earth area. The wetland area of China is approximately 15,859 square kilometers, accounting for $1.65 \%$ of its land area. The unique characteristics of multiple types, enormous extension and vast distribution of our wetland make China a resource-rich country.

\section{Wetland Tourism}

Wetland tourism, just as the name implies, is a kind of traveling activity based mainly on the wetland resources. To attract customers, many travel agencies play lots of appealing rhetoric, such as "Seaside Excursion", "Outing to Lake", "Watery Township Tour", "Recreational Fishing", and so on. Although there are some core activities related to the wetland, the term of "Wetland Tour", however, is barely seen. But as long as casting a closer eye to the ecological tendency of wetland tourism, it is not hard for us to notice the greater frequency and wider recognition of "Wetland Tourism". For instance, during Mayday Golden Week in 2005, Hangzhou Xixi National Wetland Park opened. It is the first national wetland park in the whole country. And in the same month, the National Ministry of Construction approved to set up another nine national wetland parks. In May 2006, Hong Kong, known as the "paradise of shopping", branded itself of wetland resort---opening up to all people, attracting more than 2000 tourists per day. A month later, Panjin, Liaoning brought up the plan of constructing wholeheartedly the seashore leisure center to build Panjin a world-famous wetland ecological tourist area within 10 years. Predictably, wetland tourism will soon turn the page of the contemporary tourism industry of China.

\section{The Status and Problems of Wetland Tourism Development}

The Status of Development of Wetland Tourism. Wetland bears great significance to people's life, and even to the existence of the earth. However, though known as "kidney of earth", wetland hasn't been given much attention, and the decreasing trend of it hasn't been contained efficiently. According to the latest statics, the wetland area is consistently decreasing and its function is continuously declining, posing great impact on the ecological security as well as social and economic development.

By the end of 2012, the national wetland parks in China have mounted to 43, maintaining a slow growth rate since 2004 when the assessment of national wetland park started. But this measure does not practically work out, no matter from the quantity or the distribution.

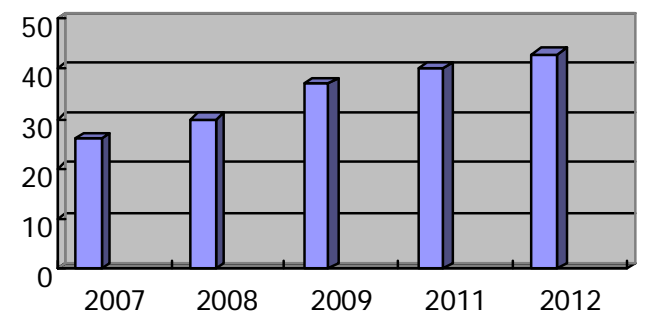

Fig. 1 The quantity of national wetland parks in China

The wetland resources that exist in the fragile ecological area are characterized by small environmental content and weak abilities of anti-disturbance. In consideration of the complexity of human activities, the exploitation of tourist resources must pay attention to the chose of developing mode and the division of function areas under the principle of ecological safety. At present, the wetland eco-tourism still adopts the simple mode of sightseeing tour, and the annual tourists' number is small. Thus, the negative impact of tourist activities hasn't appeared entirely. With the 
further development of wetland ecotourism, it will be an inevitable trend for coastal wetland tourism to seek to a comprehensive exploiting mode that gives consideration to economic, social and environmental benefit.

Though still in the early stage of development, the wetland tourism has begun to take shape. Apart from wetland ecological tours and the traveling theme park of wetland, many tourist areas have set to make initial functional divisions, translating the simplex natural preservation regions into entertaining ecological tourist areas.

Problems of Exploitation of Wetland Tourist Resources. (1) Conflict between Wetland Tourism and the Environmental Protection. Wetland belongs to the fragile ecological area, and is allergic to the change of environment. People will inevitably contradict with the environment during the exploitation, and the contradiction was not prominent at the early stage at which human's intervention of nature was still small. But the increasingly grave intervention and destruction due to the growth of population and technology has further influenced the survival of human being around the wetland, or even wider areas. In the development of wetland tourism, the conflict between economic and environment protection as well as traditional culture preserve has been an objective existence that can't be avoided. (2) Ambiguity of Wetland Ecological Tourism Theme and Low Popularity of Scenic. Although wetland resources come out first in China, the exploitation of it has always been at a low level for the inadequate utilization of its advantages, which can mainly be seen in the simplex traveling activity, simple form, and the monotonous content. (3) Restrained Development of Wetland Ecological Tourism Caused as Result of Little Investment. The allocation of local government on which the wetland ecological tourism development mainly relies is far from enough for the extent and scale of the exploitation. Besides, the management often takes one-way operation, rather than overall plans.

\section{Development Strategy of Wetland Tourism}

Put Step-up Effort to Development and Make a Comprehensive Tourism System. Putting greater effort to the development of wetland tourism requires us to do the followings: (1) To make full investigation and accurate project targeting, which means setting up a task force to implement the constructing plans of wetland park, making sure the exploitation be undertaken without damaging the environment. (2) To project at a high starting point, while putting in the professional designs. To ensure the quality of wetland park construction and to maintain the ecological environment, we must establish strategic management plans to guide the design of wetland parks. (3) To formulate a leading standard and create a theme concerned with nature. That is, to adhere to the principle of environmental protection in the process of construction of Wetland Park, such as hiding the tourists center under the artificial slopes that are mainly made of natural materials, using local wetland plant species as much as possible, adopting high-efficiency geothermal system, minimizing tourist noise influence on birds and so on. As regard the general layout of landscape belts, we can make selective exploitation for some nodes, while designating and connecting the traffic routes to gradually make up an all-around comprehensive tourist system, in which the sightseeing, participation and entertainment are combined together.

Unified Development and Partition Management. Wetland tourism development is an acting of generality, and the extensive exploitation on homogeneous resources will cause chaos and obstacle the management of the whole area. The partition management should be based on the unified development. At the same time, the core areas must be given well protection in which any type of tourist activities are forbidden. The buffer zone set strict limit to the number of tourist 
projects and the density of tourists, only allowing sightseeing and science popularization activities while letting in a portion of people in a restricted time.

Complete Managerial Plans and Regulations. Complete management plan and the rules as well as regulations are the premise and guarantee of the sustainable development of wetland tourism. The content of those plans should target at the coordinate and control of the managers, tourist and the community residents; the protection and rescue of the flora and fauna, the key protected objects in particular, of the wetland. Besides they should also take the tourists' security and the corresponding solutions into consideration when encounter an emergency. Also, the system of rewards and punishments must be in place efficiently. A complete system of managerial plans and regulations ought to be set up to manage the construction of wetland for efficient protection.

Publicity and Instruction to Residents in Wetland Tourist Zone. Through publicity and instruction, we may establish the ecological concept of taking care of wetland resources and protecting wetland environment among people. We may also encourage the educated people to spread that idea to others. In China, the practice of making use of the "Wetland Day" for ecological publicity and adding some content related to the wetland protection into the primary and secondary textbooks have seen a good outcome. The facts prove that only by establishing a ecological idea on a universal scale can we improve and protect the traveling environment efficiently and fulfill the sustainable development of wetland tourism.

Reinforcement of Ecological Monitor and Establishment of Managerial Information System. The wetland eco-system is basically well preserved and is contaminated in a relatively low level. But the development of wetland tourism will more or less cause adversely impact on it. That is why we should monitor the wetland environment in those tourist zones, especially in the natural preservation areas, and keep analyzing and predicting the possible influence that the tourism exploitation may have on the ecological environment. Then we can find out the potential problem and solve them, remedy them without delay, making sure the ecological tourism development toward a healthy and orderly direction.

\section{Conclusions}

Wetland belongs to the fragile ecological areas. Sustainable development concept must be introduced into the process of development. We should try to meet the demand of tourists and local residents while keeping and strengthening future developing chance on the base of resource protection. In practice, we have to adhere to the principle of sustainable development of wetland tourism, actively guiding the public to participate in the planning of strategy, the protection of wetland basic ecological process, biological diversity and culture and heritage integrity. That is the inevitable way to achieve the sustainable development of wetland tourism.

\section{References}

[1] Hamdar B. An efficiency approach to managing Mississippi's marginal land based on the conservation reserve program (CRP). Resources, Conservation and Recycling, 1999(26):15-24.

[2] Bolund P, S Hunhammar. Ecosystem service in urban areas. Ecological, 1999(29):293-301.

[3] Regina Scheyvens. Ecotourism and the empowerment of local communities. Tourism Management.1999, 20(2):245-249.

[4] Lisa M. Campbell. Ecotourism in rural developing communities. Annals of Tourism Research, 1999, 26(3):534-553. 